\title{
Private sector action for women's health and empowerment: How business can invest in women and realize returns
}

Robyn Russell

Ilze Melngailis

Andrea Lilja

Elissa Goldenberg

Lisa Staxang

See next page for additional authors

Follow this and additional works at: https://knowledgecommons.popcouncil.org/departments_sbsr-rh How does access to this work benefit you? Let us know!

\section{Recommended Citation}

Russell, Robyn, Ilze Melngailis, Andrea Lilja, Elissa Goldenberg, Lisa Staxang, Carolyn Rodehau, and David Wofford. 2017. "Private sector action for women's health and empowerment: How business can invest in women and realize returns." UN Foundation, BSR, The Evidence Project, and Meridian Group International. 


\section{Authors}

Robyn Russell, Ilze Melngailis, Andrea Lilja, Elissa Goldenberg, Lisa Staxang, Carolyn Rodehau, and David Wofford 


\section{PRIVATE SECTOR}

\section{ACTION FOR}

\section{WOMEN'S HEALTH}

\section{AND EMPOWERMENT}

\section{How Businesses Can Invest in Women and Realize Returns}

\section{INTRODUCTION}

\section{Contents}

This brief will expand the business case for private sector investment in women's health and empowerment in three sections:

- OPPORTUNITIES FOR ACTION

Section 1 outlines eight key actions companies can take to expand their investments in women's health and empowerment or kickstart new investments, highlighting 21 leading companies to illustrate models for action.

- MAPPING

Section 2 provides a mapping of where companies, suppliers, NGOs, and others are

implementing women's health programs to support information sharing and collaboration. Annexes 1 and 2 include a full mapping and descriptions of key implementing organizations.

\section{- RECOMMENDATIONS}

Section 3 zooms out and outlines four recommendations for future consideration and collective action by companies, suppliers, NGOs, labor organizations and governments.
In 2015, all 193 United Nations (UN) member countries signed on to the UN Sustainable Development Goals (SDGs) for 2030, setting a bold agenda to lift millions out of poverty and improve the health and wellbeing of people and planet. This critical global agenda recognized the centrality of gender equality and the health and rights of girls and women-emphasizing them in SDG 5: Gender Equality and SDG 3: Good Health \& Well-Being - as key drivers of development, prosperity, and every other SDG. Also included in the SDGs, for the first time, was an emphasis on the critical role of the private sector in reducing poverty and improving health and empowerment (SDG 17: Partnerships).

As the Business and Sustainable Development Commission recently noted, not only do the SDGs need the private sector, but the private sector needs the SDGs in order to open new opportunities, grow markets, and enhance reputations. ${ }^{1}$ Increasingly consumers make purchasing choices based on social and ethical credentials of brands. Combine this realization with the recent finding by McKinsey Global Institute that $\$ 28$ trillion could be added to annual global gross domestic product by allowing women to participate in the economy at the same rates as men, ${ }^{2}$ and the business case for private sector investment in women's health, well-being, and equality becomes clear.

Over the next two decades an estimated 1 billion women will enter the global workforce, and approximately 94 percent of these will be in emerging and developing economies. For many of these women, a job in a factory or on a farm may be their first formal employment, they may be migrating from rural to urban settings, and they often The private sector - particularly companies with supply chains that employ disproportionate numbers of women such as apparel, agriculture, home goods, and electronics - are uniquely positioned to reach millions of women with the bealth and empowerment information and services they need to improve their lives.

Business \& Sustainable Development Commission. (2017). Better Business Better World Executive Summary.

2 Woetzel, J. et al., McKinsey Global Institute. (2015). How Advancing Women’s Equality Can Add \$12 Trillion to Global Growth. 
lack access to basic health information and services in addition to other critical life skills needed to live healthy, empowered lives. The private sector-particularly companies with supply chains that employ disproportionate numbers of women such as apparel, agriculture, home goods, and electronics—are uniquely positioned to reach millions of women with the health and empowerment information and services they need to improve their lives. An estimated 60 to 75 million people, three quarters of whom are women, are employed in the textile, clothing, and footwear sectors alone. ${ }^{3}$ Communications companies are also leveraging their expertise and networks to reach women with health and empowerment information.

Companies are beginning to realize the vast benefits of investing in the health and well-being of female workers. To date, more than 1,400 CEOs have signed a statement of support for the Women's Empowerment Principles, a set of seven principles developed by the UN and the UN Global Compact, to guide businesses as they promote gender equality and women's empowerment. ${ }^{4}$ In July 2017, 10 pioneering companies from a variety of sectors ranging from Lindex, a Swedish apparel company; to Twinings, a tea company; to MTV and Viacom, announced commitments to reproductive health and family planning programs at the London Family Planning Summit. ${ }^{5}$ Dozens of other companies are partnering with non-governmental organizations (NGOs), governments, and others to create and implement health and empowerment programs designed to improve women's health while also improving business outcomes. For instance, over 60 companies in various supply chains such as apparel, agriculture and electronics, have worked with the nonprofit business network Business for Social Responsibility (BSR) in 12 countries and more than 600 factories to implement workplace women's health and empowerment programs. These programs have reached over 700,000 women in global supply chains.

3 Stotz, L. et al., Clean Clothes Campaign. (2015.) Facts on the Global Garment Industry.

4 UN Women. (2017). Women's Empowerment Principles.

5 Family Planning 2020. (2017). New Commitments.

\section{WHY INVEST IN WOMEN'S HEALTH AND EMPOWERMENT?}

This brief reviews 26 various private sector investments ${ }^{6}$ in women's health and empowerment. These range from workplace programs led by apparel, agriculture, consumer goods, microfinance, and electronics companies; to investments in technology, information, and networks by communications companies to improve women's health and wellbeing. While these programs vary, three themes emerge:

1. Workplace health and well-being programs have been shown to significantly improve worker health and empowerment. For example, clothing company Marks \& Spencer partnered with Project Hope and the Reproductive Health Association of Cambodia (RHAC) to deliver health services to over 14,000 workers in 7 factories. They saw a 60 percent reduction in anemia, a 40 percent increase in workers accessing the factory clinic, and a 15 percent increase in referrals by factory clinic to external clinics. Similarly, ANN INC., a specialty retailer through its brands Ann Taylor, LOFT and Lou \& Grey, partnered with BSR to provide basic health information in factories in six countries through HERhealth, an initiative that has shown a 41 percent increase in knowledge of maternal and child health care, a 32 percent expansion in the adoption of voluntary family planning, and a 26 percent increase in improved diet.

2. Worker health and well-being programs have proven to reap business benefits including: increased productivity, reduced absenteeism, and improved worker satisfaction. ${ }^{7}$ BSR found that investments in work place women's health programs result in 4:1 return on investment to companies. ${ }^{8}$ Similarly, a USAIDsupported study of the effects of workplace health service delivery

6 While this brief focuses on company investments, it should be noted that donors such as USAID, DFID, GIZ, SIDA and others have supported workplace women's health programs for many years, often collaborating with companies on programs.

7 International Center for Research on Women (2016) A Comprehensive Evaluation of the GAP Inc. P.A.C.E. Program

8 Yeager, R. (2011). Business for Social Responsibility, HERProject: Health Enables Returns.

\section{HERHEALTH IMPACT}

The HERhealth program is delivering real results. Across the participating factories, the following improvements have been observed amongst female participants:

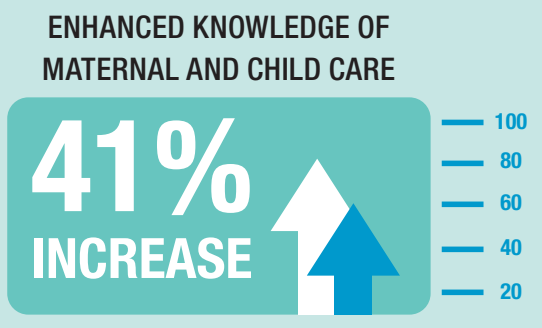

in participants knowing the importance of exclusive breastfeeding in the first 6 months

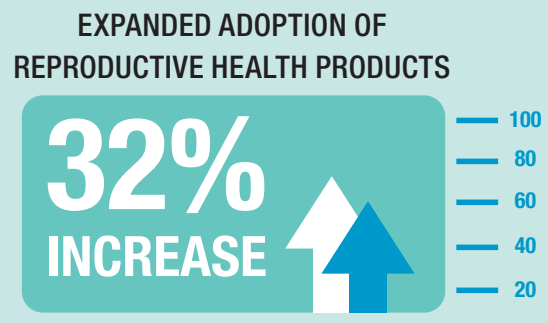

in use of family planning methods
IMPROVED DIET

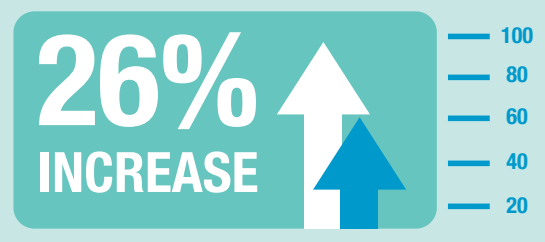

in participants eating healthier 
in the garment factories in Bangladesh found that provision of on-site health services; including general health, pre-natal care, digestive health, and voluntary reproductive health and family planning; resulted in an 18 percent decline in absenteeism, and a 43 percent decrease in staff turnover, indicating an overall return on investment of 3:1. ${ }^{9}$ Factory workers reported the availability of onsite services made them less likely to be absent from work, more likely to stay in their current job, and improved positive attitudes

Provsion of on-site health services resulted in an overall return on investment of 3:1. toward factory management.

Consumers also increasingly make purchasing decisions based on a product's social good, according to recent research. ${ }^{10}$

Critical to note is that these two rationales are not distinct but mutually reinforcing. Every brand, supplier, NGO, and program participant consulted shared that worker health and empowerment improvements were directly linked with business improvements such as reduced absenteeism and increased productivity. When women feel healthy and empowered, they are better able to communicate with management, take on leadership roles themselves, and are ultimately happier and more productive.

3. In addition to investments in workplace programs, communications companies such as Qualcomm, Vodafone, and MTV with Viacom have begun using their communications expertise and networks to increase access to women's health and empowerment information and services. They are expanding consumer reach and growing markets while also improving lives-a win-win.

\section{CONTENTS}

This brief expands this business case for private sector investment in women's health and empowerment in three sections:

- OPPORTUNITIES FOR ACTION-Section 1 outlines eight key actions companies can take to expand their investments in women's health and empowerment or kickstart new investments, highlighting 21 leading companies to illustrate models for action.

- MAPPING — Section 2 provides a mapping of where companies, suppliers, NGOs, and others are implementing women's health programs to support information sharing and collaboration. Annexes 1 and 2 include a full mapping and descriptions of key implementing organizations.
- RECOMMENDATIONS - Section 3 zooms out and outlines four recommendations for future consideration and collective action by companies, suppliers, NGOs, labor organizations, and governments.

\section{OPPORTUNITIES FOR ACTION}

In order to achieve the health, empowerment, and business benefits of investing in women, we offer a road map for concrete actions. Outlined here are eight opportunities for action, models for those actions, and examples of potential implementation partners for companies to consider as they design their strategies to contribute to achievement of the SDGs.

\section{ACTION 1: \\ Make a public commitment.}

Business leaders can start by making women's health and empowerment explicit in their commitments to the UN SDGs. Such commitments drive strategies and investments targeting the health and well-being of women, and could include commitments to worker health and empowerment through workplace programs or leveraging networks and expertise to reach women with needed information and services. Some opportunities to make a public commitment aligned with the SDGs in this area include:

- EVERY WOMEN EVERY CHILD (EWEC): This initiative led by the UN implements the Global Strategy for Women's, Children's and Adolescents' Health5 in support of the SDGs. http://www.everywomaneverychild.org/

- FAMILY PLANNING 2020 (FP2020): This global partnership supports the rights of women and girls to decide, freely, and for themselves, whether, when, and how many children they want to have. http://www.familyplanning2020.org/

\section{- THE WOMEN'S EMPOWERMENT PRINCIPLES} (WEPS): The WEPs comprise seven principles, including one on health, for business, developed by UN Women and UN Global Compact, offering guidance on how to empower women in the workplace, marketplace, and community. http://www.weprinciples.org/

Ten companies at the 2017 Family Planning Summit in London ${ }^{11}$ made new commitments to expand access to family planning and women's health through their own operations. The following two corporate highlights include Lindex and Twinings.

\footnotetext{
11 The summit was hosted by the Bill \& Melinda Gates Foundation, the UK government, and the UN Population Fund, in partnership with Family Planning 2020. The commitments were made to both FP2020 and EWEC.
}

9 USAID. (2007). Effects of a Workplace Health Program on Absenteeism, Turnover, and Worker Attitudes in a Bangladesh Garment Factory.

10 Hainmueller, J. (2015). Review of Economics and Statistics, Consumer Demand for Fair Trade: Evidence from a Multistore Field Experiment. 


\section{CORPORATE HIGHLIGHT: Lindex}

\section{LINDEX Lindex, a Swedish \\ fashion chain with \\ approximately 480 \\ stores in 17 markets, \\ launched WE WOMEN,}

a 3-year program to provide technical, financial, and health training to 83,500 workers, including more than 50,000 women in Bangladesh. Suported by GIZ, a German development agency, and BSR, WE WOMEN will also incorporate gender equality into management systems and provide support and training to encourage career advancement for female employees. Lindex began investing in the health of workers in its supply chain in 2012, working with BSR to run the workplace women's health program, HERhealth, in factories in Bangladesh, Pakistan, and India, reaching 12,000 women. Through their investment in workplace health Lindex saw returns on both health outcomes and business indicators. They documented improved worker health knowledge, such as prevention of sexually transmitted infections; nutrition; and hygiene, improved hand washing and use of sanitary napkins rather than dirty cloth. The factory observed less sick leave and staff turnover due to improved health. Managers had better understanding of the needs of female workers and workers and management communicated better.

This expanded investment in women workers through WE WOMEN to the entire workforce in Bangladesh - a country which produces 45 percent of Lindex's total productionmarks a significant increase in the company's commitment to women's health and empowerment. Lindex plans to scale this program to the rest of their supply chain in India, Pakistan, Turkey, China, Myanmar, and
"Our customers are women, we are mainly women working in Lindex, and most of the people working in our supply chain are women. We want Lindex to be a leading fashion company in women's empowerment."

-Elisabeth Hedberg,

Lindex's Director of Production

Cambodia. For Lindex, with so many female customers and so many female workers, investing in women's health and empowerment just makes sense.

\section{CORPORATE HIGHLIGHT: Twinings}

\section{Twinings, an
international}

tea company, is implementing BSR's HERhealth project with smallholder farmers and tea workers in Kenya, most of whom are women. It will provide them with information on reproductive health and family planning, sexually transmitted infections, menstrual hygiene, pre- and post-natal care, nutrition, and non-communicable diseases. Twinings has already reached over 1,000 workers and is working to cover 40,000 60 percent of women in their supply chain in Kenya. The program has already shown returns. Health knowledge on key topics such as family planning, HIV, Hepatitis B, and pregnancy

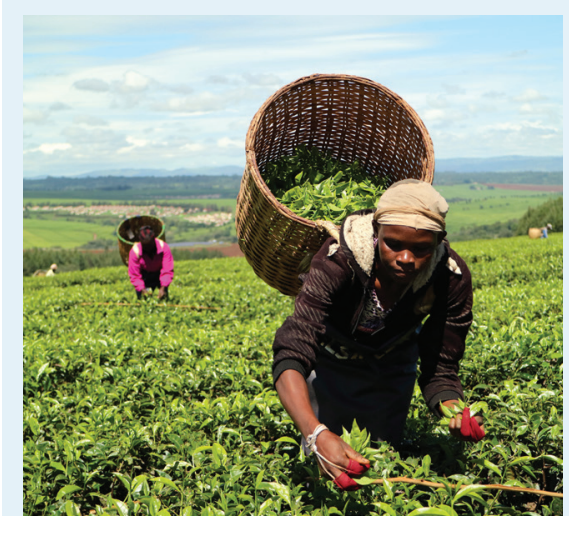

health have improved significantly. Women able to name a family planning method increased from 30 to 100 percent; women's knowledge of mother to child transmission of HIV increased from 9.5 percent to 77 percent; and women able to name three or more pregnancy risk factors increased from 11 percent to 86 percent.

Twinings has also seen improved health behavior with an increase in the use of health facilities following trainings; improved worker relations with management, with workers feeling more comfortable discussing issues with their managers; and reductions in absenteeism, leading to improved productivity in the workplace. Céline Gilart, Head of Social Impact at Twinings, explained: "Healthier, empowered and sustainable communities are essential to ensuring strong supply chains, but also we believe working to improve lives in our supply chain is the right thing to do. Women form most of the workforce in tea gardens, but sexual health and reproductive rights can be a barrier to their development. When women and girls thrive, so do their societies. That's why we are committed to empowering women in our supply chain through health and education."

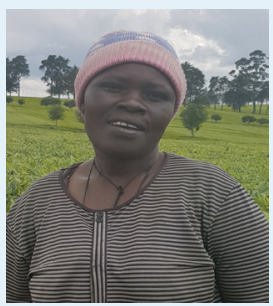

Irene is a mother of three who has worked as a picker on a tea estate in Kenya for 10 years. "Before the HERhealth project training on family planning, I suffered a lot," said Irene. "I gave birth to my three children every year one after the other, and I realized this was affecting my health and leading to low productivity at my workplace. I was determined to find a way of stopping giving birth because it weakened me, and also I realized the burden that came with having a big family." Iren wanted to use contraceptives, but her husband would not let her. Through the HERhealth program, Irene received training, and these new skills and knowledge enabled her to speak to her husband about family planning. Today Irene use uses a contraceptive that works for her, and she and her husband have made a decision not have more children. "I now live happily with my husband," said Irene. 


\section{Invest in women's health and empowerment information.}

Workers often lack access to basic health information including on family planning, menstrual hygiene, nutrition, pre-natal care, and other life skills. Companies can start by ensuring workers in their operations and global supply chains have access to quality health information. Information is power, and sharing knowledge is vital step to help women workers, particularly in less developed countries, understand their bodies better and control their futures. Providing information can take many forms:

FORMAL HEALTH EDUCATION PROGRAMS: As outlined in ANNEX 1, there are a number of organizations with networks around the world and deep experience implementing highly effective programs to improve worker health and empowerment.
MOBILE MATERIALS: As mobile phone use increases globally, companies can use mobile devices to connect workers with health information and services. Qualcomm and Vodafone have worked with implementers to develop mobile applications to improve access to health information.

\section{OPEN-ACCESS PRINTABLE POSTERS AND}

HANDOUTS: There are a number of free, printable, open-source materials with rich health information available online for consumption by workers, managers, and workplace health providers. For instance, the USAID-funded Evidence Project and Bayer released a set of free, printable materials to improve access to health information for women workers, available at: www.your-life.com/workplace

\section{CORPORATE HIGHLIGHT: $\boldsymbol{A N N}$ INC.}

\section{ANN INC. ANN INC., a specialty An tancon | LOFT | Lou o orer retailer through its brands Ann Taylor, LOFT and Lou \& Grey, encourages its} suppliers to provide women's health education and services in its factories. As part of ANN INC.'s 100,000 Women Commitment, they aim to empower women in their global supply chain to reach their full potential, partnering with BSR to implement HERhealth. ANN INC. has sourced 72 percent of its apparel through partners that provide their workers with the HERproject curriculum, operating in six countries - China, Bangladesh, India, Vietnam, Philippines, and Indonesia-57 factories, training 2,200 peer educators, and impacting 82,000 women. In India, HERproject has seen a 67 percent increase in women reporting to have a say in the decision-making regarding family planning,

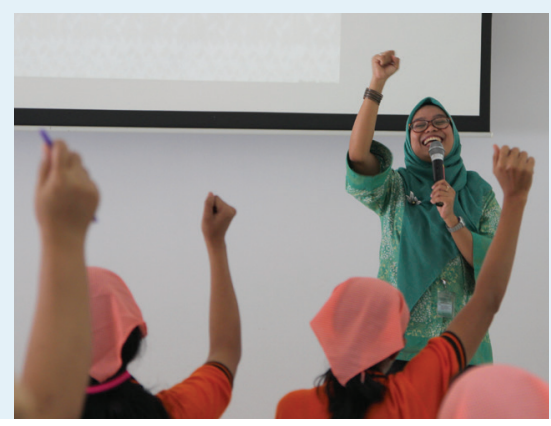

and a 30 percent increase in women using family planning. In Bangladesh, HERproject has seen a 49 percent increase in women able to mention at least 3 risk factors during pregnancy requiring medical help. According to Jeannette Ferran Astorga, Vice President of Corporate Responsibility at Ascena Retail Group Inc., parent company of ANN INC., "We are committed to empowering women in our supply chain by partnering with BSR to implement the HERproject, a program that has resulted in improved health outcomes for these women and strengthened relationships and business outcomes with suppliers."

In 2013 ANN INC. asked its supplier, PT Tainan, in Indonesia to implement HERhealth in order to provide workers with information on topics ranging from nutrition, to sanitation, to reproductive health, and more. Four years later the workers are healthier and more empowered, and the factory has seen improvements in retention, absenteeism, and morale. Healthier, happier workers are also more productive- $\mathrm{a}$ win-win for both the women and the factory.

Jerry Chang, director of one of ANN INC.'s supplier factories in Indonesia, summed up the benefit of investing in women's health and family planning, saying, "We see improvement in absenteeism, a 50 percent reduction in turnover, and in turn it helps with the productivity. ... The health of these female workers is an asset of the company ... it uplifts the whole factory."

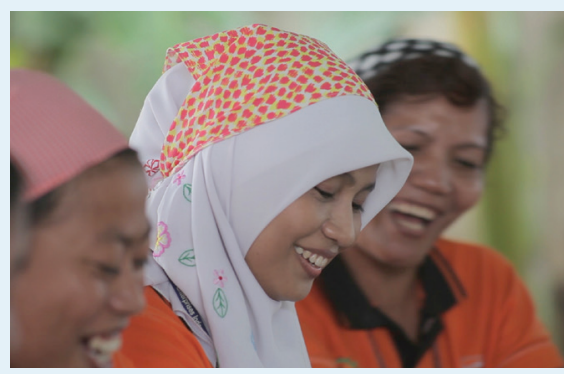

Khoeriyah, a worker at TP Tainan who supports both of her parents with the income she earns preparing patterns at the factory, also shared how the health education she received through the factory has impacted her life, saying, "I am fortunate that in Tainan Enterprise we have HERproject that provides information on contraception... I want to have two kids: one boy and one girl ... I can plan a better family with two kids. First and foremost I consider the funding for the education." Khoeriyah also noted the impact the program has had on her coworkers, explaining, "Without the HERproject, employees would not be able to plan their families - they would not know how to use contraception." 


\section{CORPORATE HIGHLIGHT: Jabil}

JABIL

Jabil is a US-based

global manufacturing

services company

with 90 facilities

in 23 countries,

and 175,000 employees worldwide. Women comprise approximately half of Jabil's workforce, and in response to the unique needs of their female employees, in 2009, in partnership with BSR, the company began implementing the HERhealth program to provide family planning and reproductive health education, life coaching, team building and self-esteem and wellness programs to female employees in seven factories in China. To date, nearly 60,000 employees have participated, reaching an additional 240,000 colleagues, family, and community members with important messages and knowledge on women's health. Jabil has seen improvement in both the health and empowerment of female employees, as well as business returns. One worker who participated in the workplace program explained how the program has impacted her life, saying, "Jabil's investment in women is very important. For instance, it provides me with an employment opportunity, as well as an opportunity for self-improvement." Jabil currently implements the HERhealth program in six factories in China and one in Vietnam, and is expanding the program to India.
"Not only did absenteeism go down, and visits to health clinics on the factory campus and employee engagement go up, but the women shared what they learned with their families, their friends, and throughout their communities."

-Eric Austermann, Jabil's Vice President of Social \& Environmental Responsibility

\section{CORPORATE HIGHLIGHT: Qualcomm}

QuALCOMM: Wireless Reach - Qualcomm, a global actor in 3G, 4G and next-generation wireless technologies, through its Qualcomm ${ }^{\circledR}$ Wireless Reach ${ }^{\mathrm{TM}}$ initiative, funded the Mobilizing HERhealth program which created the HERhealth mobile application, an app that allows workers convenient access to five modules on reproductive structure, common gynecological diseases, family planning and maternal healthcare, HIV prevention, and mental health, via their mobile phones. To improve access to health services, the app also features a map of hospitals and clinics near the factories as well as links to websites where women can make doctor appointments. To date, the mobile application has been implemented in 34 factories across China reaching 3,500 women workers. In 2018, Qualcomm Wireless Reach will explore expanding the program to other countries.

\section{The Qualcomm ${ }^{\circledast}$ Wireless Reach ${ }^{\mathrm{TM}}$ initiative} funded the Mobilizing HERhealth program which created the HERhealth mobile application, an app that allows workers convenient access to five modules on reproductive structure, common gynecological diseases, family planning and maternal healthcare, HIV prevention, and mental health.

\section{TESCO \\ CORPORATE HIGHLIGHT: Tesco and Welspun}

W WELSPUN INDIA

Tesco, a British multinational grocery and general retailer, and Welspun, an Indian textile manufacturer and key supplier to Tesco are implementing HERhealth in India. Currently 120 peer educators are being trained, reaching 3,500 women, family, and community members with information on nutrition, hygiene, reproductive health, family planning, and other topics. The program also seeks to strengthen the factory health management systems using BSR's clinic assessment toolkit to assess factory clinics and improve access to services and products. Tesco and Welspun aim to reach over 5,000 women in total.

\section{ACTION 3:}

\section{Invest in women's health and empowerment through expanded services and improved policies.}

Through their expansive workforces, supply chains, and communications networks, companies can use their reach, resources, and expertise to reach millions of women and their families with much-needed health and empowerment services to both improve women's health and well-being while also improving business bottomlines. Programs and policies should be rooted in voluntarism and informed consent and include a focus on reproductive health, as the ability to choose when one becomes a parent is a critical and currently 


\section{corporate highlight: Kombolcha Textile Factory}

Kombolcha Textile Factory, employs more than 2,200 workers, half of whom are women, partnered with International Planned Parenthood (IPPF) Member Association in Ethiopia, Family Guidance Association of Ethiopia (FGAE), to set up clinics for workers delivering a wide range of sexual and reproductive health services. This partnership was spurred by the high rate of unintended pregnancies, complications during pregnancy and childbirth, and lack of antenatal and obstetric care for workers. Approximately 50 percent of the female workforce were on extended sick leave, severely affecting productivity and costing the company significant sums to find temporary workers to cover those who were out sick. In less than four years, the partnership saw new cases of STIs and HIV infections reduced to almost zero, an uptake of voluntary, modern family planning methods from 11 percent to 90 percent, dramatic reductions in unintended pregnancies, and improved access to quality antenatal and obstetric care, all leading to a significant reduction of maternity and sick leave and pay. As women were able to plan their pregnancies and access quality health services, their health improved and they were able to dedicate more time to their work. Skilled staff were retained

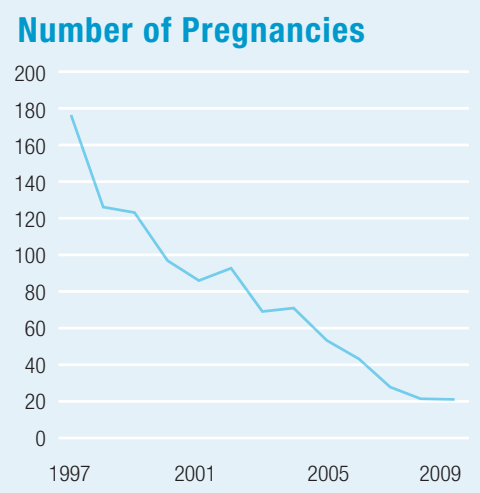

and the need for temporary workers was reduced. The factory owners saw so much value in the program that they set up their own clinics with trained service providers on site.
Improving access to high-quality voluntary health services can reduce sick leave and maternity-related leave. Still companies should also pursue gender-sensitive policies, including improved sick and maternity leave.

\section{CORPORATE HIGHLIGHT: Marks \& Spencer}

\section{$M \& S$}

EST. 1884

\section{Marks \& Spencer \\ (M\&S), a British \\ multinational retailer \\ has partnered with \\ NGOs in Cambodia,}

Kenya, India, Vietnam, and Bangladesh to implement workplace women's health and empowerment programs. In Cambodia, M\&S partnered with Project Hope and the Reproductive Health Association of Cambodia (RHAC) to deliver health services to over 14,000 workers in 7 factories under a program called HEALTHWORKS. Initiated in response to concerns following reports of fainting among women workers, employees were provided health education on topics including reproductive health and family planning, anemia, hydration, nutrition, and hygiene and sanitation. Additionally, on-site clinic staff were trained to provide more effective information, basic medicines, and referrals to community clinics. The program resulted in a 60 percent reduction in anemia, a 40 percent increase in workers accessing the factory clinic, and a 15 percent increase in referrals by factory clinic to external clinics. The program produced a strong business case and return on investment with an average 5 percent reduction in absenteeism and 7 percent increase in production efficiency across all 7 factories. HEALTHWORKS has continued in M\&S factories with a further 10 factories participating, 15,000 workers trained on basic health awareness, and 22 clinic health staff provided with health service and information skills. unmet need for many women. ${ }^{12}$ Companies can take action through investments in services and improvements in company policy.

\section{EXPAND SERVICES: As outlined in ANNEX 1, there are a number} of organizations with expertise and experience partnering with local civil society organizations to implement low-cost, high-impact health and empowerment programs ranging from peer education models, to mobile clinics, to factory service improvement programs, to referral network strengthening efforts, to direct service delivery and more.
IMPROVE POLICIES: In order to ensure worker access to information and services provided through workplace programs, companies should review their policies and work with NGOs, civil society, and worker unions to establish effective practices on issues such as onsite clinic access and hours; access to external health services and referral systems; improved sick and maternity leave policies; insurance options and payment schemes related to health; violence prevention; and transportation needs. Companies should also strive to move beyond time-bound pilots and adopt integrated, scalable, sustainable programs throughout supply chains and networks.

12 For additional guidance on rights-based family planning see the FP2020 Rights and Empowerment Principles for Family Planning and the Call to Action: Strategies for Rights-based Family Planning 


\section{corporate highlght: Levi-Strauss \& Co.}

\section{LEVI STRAUSS} FOUNDATION

Levi Strauss \& Co.

is partnering with over 35 vendors to implement their Worker Well-being

Initiative in 12 countries including Bangladesh, China, Cambodia, Egypt, Haiti, India, Pakistan, Sri Lanka, Turkey, Vietnam, Mexico, and Lesotho. Through the Worker Well-being Initiative, LS\&Co. partners with supply chain vendors to grow beyond labor compliance and improve health, financial security, and equality for workers, with a focus on women who comprise close to 80 percent of apparel workers. Driven by local worker needs, the Worker Well-being Initiative partners with vendors and non-profits to design and implement programs providing services ranging from financial literacy and skills training courses; to sexual and reproductive health training, clinic services, nutrition and hygiene workshops; and discrimination and harassment awareness trainings. To spur sustainability, the Levi Strauss Foundation commits to funding 50 percent of the program costs during the first year, with the expectation that contributions will decrease over time as vendors incorporate the program into their operations. To date, through its Worker Well-being Initiative, LS\&Co. has reached over 130,000 workers and

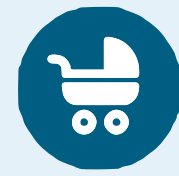

BANGLADESH

More women returned after maternity leave

\section{BUSINESS RETURN}

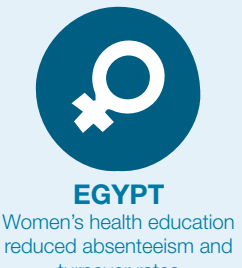

turnover rates

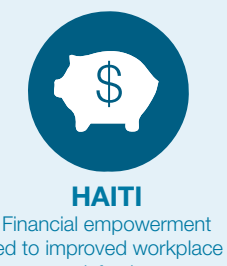

satisfaction

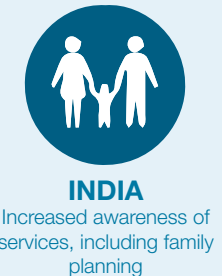

planning

Key business returns Levi Strauss \& Co. has seen through their Worker Well-being Initiative.

plans to reach more than 200,000 by 2020 (representing 80 percent of their supply chain). LS\&Co. sees improving working conditions and opportunities for women - and all workersas an investment, not a cost. In the supply chains where LS\&Co. has implemented worker well-being programs, manufacturers have seen increased outputs and reduced absenteeism, turnover, overtime, production errors, and return rates. LS\&Co. vendors implementing BSR's HERproject saw returns of $4: 1$.

LS\&Co. is using its position as a global brand to encourage systemic change and widespread adoption of worker health and well-being programs throughout supply chains, encouraging other manufacturers to invest in five priorities areas-skill development, pregnancy and parenthood, menstruation, wages and work hours, and

\section{"From here on out, it is simply what we expect and how we do business with our global suppliers.” -LS\&CO. President and CEO Chip Bergh}

harassment-in order to improve worker health and well-being and business performance. Together with Meridian Group International Inc., the Levi Strauss Foundation created a guide book for others in the apparel industry"Managing Health at the Workplace"a_which offers a health score card so that factories can assess their health needs and eight "how-to" modules for managers to improve health, management, budgeting, and data collection.

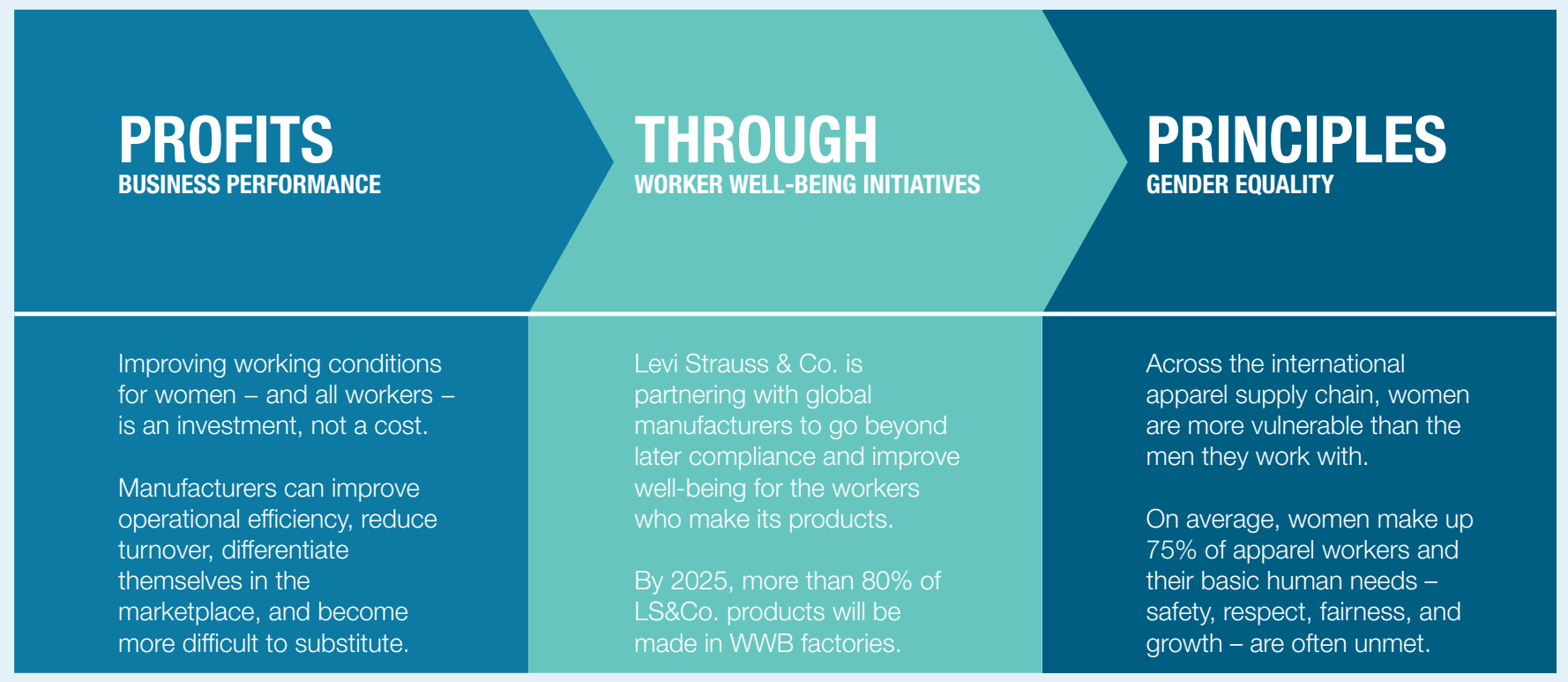

Levi Strauss \& Co.'s vision to improve business performance through gender equality. 


\section{CORPORATE HIGHLIGHT: $\boldsymbol{C A R D - M R I}$}

CARD-MRI (Center

for Agriculture and

Rural Development-

Mutually Reinforcing

Institutions), the

largest micro-finance institute in the Philippines, is investing \$2.1 million USD and utilizing its extensive micro-finance network to reach at least 4 million women with reproductive health information and services. Under this campaign, CARD-MRI women-members receive weekly 15-minute learning sessions on modern family planning, breastfeeding, maternal health, pre-natal health, HIV/AIDS, breast and cervical cancer, proper heart care, and smoking cessation, during an eight-week module. In addition to the provision of reproductive and basic health information, CARD-MRI also provides general medical services, wellness check-ups, dental services and family planning counselling and services, leveraging its own chain of pharmacies to supply medicines and contraceptives including pills and condoms to its clients at discounted prices. CARD-MRI, together with UNFPA, will train all its doctors and nurses on modern family planning services and deploy 17 nurses around the country to provide family planning services, including contraceptive implants, and other health services. Finally, CARD-MRI is partnering with 18 other micro-finance institutions in the Philippines to provide Community Health Days, where free health and dental check-ups are provided to millions of women and their families throughout the Philippines, and 29 community health volunteers have been trained on family planning and are now providing services to 710 women in 15 villages.

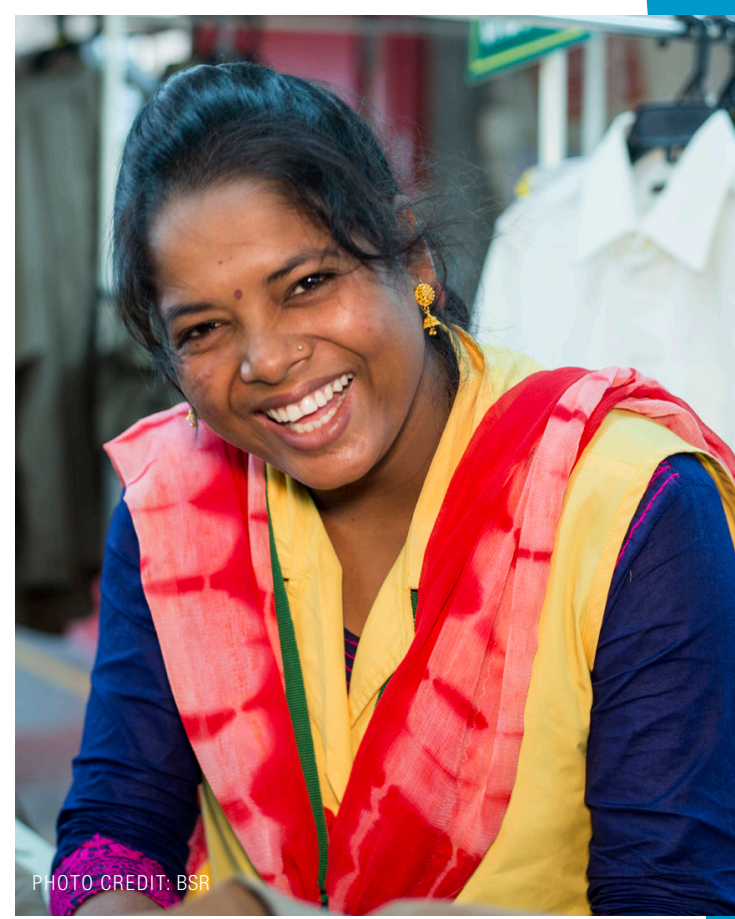

\section{ACTION 4:}

\section{Incorporate women's health into corporate women's empowerment and gender equality initiatives.}

Gender equality and economic empowerment cannot be achieved unless women are healthy and can plan their families. Companies with broader gender equality and economic empowerment initiatives should be sure to incorporate women's health into existing corporate women's empowerment and gender equality initiatives.
In Cambodia, workplace retention rates were 66 percent higher among P.A.C.E. participants compared to other female garment workers in the factory. In India, productivity was 15 percent higher for P.A.C.E. participants. And a randomized control trial in five factories in India found that the P.A.C.E. program has a return on investment (ROI) of approximately 250 percent.

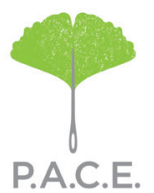

\section{CORPORATE HIGHLIGHT: $\boldsymbol{G} \boldsymbol{A P} \boldsymbol{I} \boldsymbol{n} \boldsymbol{c}$.}

GAP Inc., recognizing the lack of opportunity for career growth and need for greater life and health skills among female garment workers, in 2007, GAP Inc. launched P.A.C.E. (Personal Advancement \& Career Enhancement), a workplace education program to provide female workers the managerial, interpersonal, health, financial and other life skills and information needed to advance in work and life. Ten years later, the program has reached 65,000 women in 16 countriesBangladesh, Cambodia, China, Ethiopia, Guatemala, Haiti, El Salvador, Nicaragua, India, Indonesia, Jordan, Mexico, Myanmar, Pakistan, Sri
Lanka and Vietnam—-has expanded to adolescent girls and women in community settings, and plans to reach 1 million women and girls by the end of 2020. P.A.C.E. includes models on topics ranging from problem solving and decision making, to financial literacy and communication, to gender roles and general and reproductive health. An independent analysis of the P.A.C.E. program in five countries saw significant improvements in health and empowerment as well as business outcomes. Self-esteem improved 49 percent in program participants, and self-efficacy increased 150 percent. As Sonia, a P.A.C.E. participant in Bangladesh explained, "I have learned how to communicate effectively. Now I can solve any problem in the workplace by discussing it with my supervisor and line leader." In Cambodia, workplace retention rates were 66 percent higher among P.A.C.E. participants compared to other female garment workers in the factory. In India, productivity was 15 percent higher for P.A.C.E. participants. And a randomized control trial in five factories in India, found that the P.A.C.E. program has a return on investment (ROI) of approximately 250 percent, resulting largely from the relatively low cost of the program combined with its cumulative effects on productivity. "Our goal is to help women's voices become stronger so that they are confident in raising those voices when it comes to decisions for themselves, their families and their jobs," said Kindley Walsh Lawlor, Vice President of Gap Inc.'s P.A.C.E. program. 


\section{Collect quantitative and qualitative data on impact of investments.}

While there are dozens of private sector programs investing in women's health and empowerment around the world, data on the impact of these programs is still being collected, refined, and disseminated. Companies can benefit from monitoring and evaluating their programs and policy changes in order to document the impact of their investments, use the findings to make needed adjustments, and contribute to the business case for investments in women's health and empowerment.

INVEST IN EVALUATION: Organizations such as International Center for Research on Women (ICRW), the Population Council, UNFPA, Better Work ${ }^{13}$ and others have the capacity to document the impact of programs with companies.

13 Better Work is a joint initiative of the International Labor Organization and the International Finance Corporation with partnerships with more than 100 global brands and retailers in eight countries.

\section{CORPORATE HIGHLIGHT: $\boldsymbol{N S T}$}

\section{TNST}

NST, a Philippines-based apparel supplier for global brands such as Ann Taylor, Ralph Lauren, and J. Crew, together with its subsidiaries, Hamlin and Reliance Producers Cooperative, is planning to expand its current workplace health program to reach an additional 6,000 employees, 4,500 of whom are women, with information and services on family planning, maternal health, and basic health care. Using an ROI tool implemented by UNFPA, NST saw a savings of 5.28 Philippine Pesos for every 1 Peso invested such basic health services, including family planning, for their workers. In order to improve the health of their workers and productivity of their factories, NST is also investing in the training of nurses, human resources staff, and peer health educators on family planning methods and counseling in order to connect employees directly with services. As factory manager Dorotea M. Sarwelas put it, "The implementation of the family planning program through the joint support of UNFPA and the Employer's Confederation of the Philippines made it possible for minimum wage earners to access an expensive commodity [contraception implants] for free. This program also created a circle of mothers who are challenged to map out their family's future, achieve financial freedom, and attain work-life balance."

\section{corporate highlight: GSK, M\&SS, CARE}

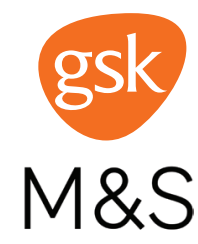

EST. 1884
GSK, M\&S,

CARE-Global

healthcare company

GlaxoSmithKline

(GSK), British

multinational retailer

Marks \& Spencer,

and CARE International partnered to empower ready-made garment (RMG) workers in Bangladesh, particularly women, through a project called Health Access and Linkage Opportunities for Workers (HALOW) aimed at improving worker and community health, strengthening health systems, and increasing factory productivity. The program trained 241 Health Champions; reached 7,700 workers with health, hygiene, and nutrition information; and partnered with the government to provide free health services in factories, including family planning services to 2,100 couples. The health clinics were renovated and eight new services were added including blood grouping, eye screening, pain management, family planning, iron folic acid for anemia, exercise and menstrual care. The project also created referral networks and connected local

\section{GSK and M\&S see great} value in investing in the bealth of garment workers, specifically female workers who comprise most of the workforce, and hope to create a scalable model to address the health and social needs of the over 4 million female garment workers in Bangladesh and beyond.

health services to RMG workers and their families. Within the year, both factories saw an improvement of 5-15 percent in factory efficiency. The tripartite partnership is now scaling up to reach 50,000 workers across 15 factories and in 10 surrounding communities. PricewaterhouseCoopers LLP (PWC) is also creating the business and social return on

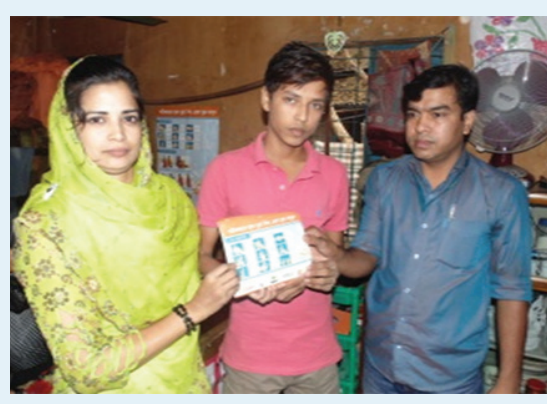

Murshida, a Health Champion trained by the HALOW project, with her son and husband said, "I would not have imagined these simple practices could have such a profound impact on my family."

investment (ROI) model so the partnership can advocate to factories to invest in the lives of their workers and their surrounding communities. GSK and M\&S see great value in investing in the health of garment workers, specifically female workers who comprise most of the workforce, and hope to create a scalable model to address the health and social needs of the over 4 million female garment workers in Bangladesh and beyond. 
ACTION 6:

\section{Integrate gender and women's bealth into corporate codes, assessments, supplier guidance, and checklists.}

Gender is usually addressed in limited ways in corporate codes of conduct and compliance checklists. Companies can make their codes more gender sensitive by ensuring policies that address the unique health needs of women workers. Companies can also integrate gender and women's health into existing assessments or due diligence, such as on the UN Business and Human Rights Principles. This includes assessing the performance of key business relationships in their global supply chains. The goal should be to go beyond narrow compliance to determine how to meet critical human needs.

\section{Gender Code}

Gender Code-The Gender Equality in Codes of Conduct Guidance, by BSR, offers a gender-sensitive analysis of codes of conduct principleswith a primary focus on women. It makes recommendations on how companies can strengthen their internal policies and standards to promote gender equality in the workplace, including worker and women's health, with particular focus on supply chains in emerging markets. Find more information at https://www.bsr.org/our-insights/report-view/ gender-equality-in-codes-of-conduct-guidance
ACTION 7:

\section{Make information public and open-access.}

Companies can advance women's health and gender equality by making impact data, tools, approaches, and materials available to everyone through forums, conferences, websites, and multi-media outlets.

DISTRIBUTE FINDINGS: Several organizations have documented and distributed impact information, such as the Population Council' ${ }^{14}$, ICRW, UNF and its storytelling work, ${ }^{15}$ and BSR's reporting. ${ }^{16}$

OPEN SOURCE: Materials from CARE \& Walmart Foundation's Women in Factories ${ }^{17}$ Initiative, Levi Strauss \& Co.'s Worker-Wellbeing Initiative ${ }^{18}$, and BSR's HERproject ${ }^{19}$ are examples of open-source workplace health and empowerment curricula.

\footnotetext{
14 Population Council (2017): Health Needs, Health Seeking Pathways, and Drivers of Health Seeking Behaviors of Female Garment Factory Workers in Cambodia and Evaluation of the HERhealth Intervention in Bangladesh

15 UN Foundation. (2016) The Women Behind the Clothes.

16 Business for Social Responsibility. (2017). About HERhealth.

17 Walmart. (2011). Women in Factories Training Program.

18 Levi Strauss \& Co. (2016). Sustainability

19 Business for Social Responsibility. (2017). Training Curriculum.
}

\section{CORPORATE HIGHLIGHT: Walmart Foundation and CARE}

Walmart Foundation and CARE — In 2011 Walmart and the Walmart Foundation launched the Women in Factories Training Program with NGO partners, including CARE, which developed the program's global curriculum. In Bangladesh, the five-year initiative has trained over 50,000 garment workers in 30 factories, with life skills on communication, hygiene, reproductive health, occupational health and safety, gender sensitivity, and targeted leadership training to support career development. An independent analysis of the program, led by Tufts University, is forthcoming, and initial data indicates positive impacts on health, gender equality, and worker-manager relationships. Hand washing, menstrual hygiene, and nutrition awareness improved, along with pride felt by workers and supervisors' attitudes toward workers. From a business standpoint, management reported a reduction in both late days and turnover, and an increase in reaching production targets. The open-source Women in Factories Training Program curriculum can be shared and adapted by other brands, organizations, factories and any other stakeholders who are interested in improving worker health, wellness, and empowerment in the factory sector. 


\section{CORPORATE Highlight: Share Hope}

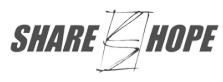

Share Hope, a social

business producing women's activewear in Haiti, has been partnering with BSR to

implement the HERhealth program since 2014, and has provided health education to 8,750 female workers in the Haitian garment sector with training modules on basic health issues, including family planning, sexually transmitted infections, personal hygiene, and nutrition, among others. Share Hope has also made this program accessible to the deaf and hard-ofhearing population in the factories. Additionally, Share Hope is running a Factory Clinic Improvement program to build the capacity of factory clinics and nurses in 12 factories. Investing in health education and services for workers in the sector has paid dividends. After receiving training, 98 percent of women in one factory signed up to receive an HIV test, and 81 percent felt their health had improved due to their participation in the program. Share Hope also saw these health improvements translate into business improvements. Due to their better understanding of basic health practice, 87 percent of workers reported taking fewer days off from work because of illness.

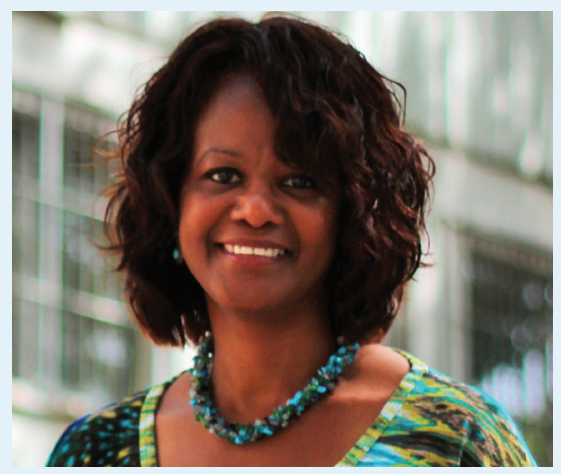

Cynthia Petterson, CEO of Share Hope

Cynthia Petterson, CEO of Share Hope, shared, "What makes workers happy is going to make for a more productive environment, and the business runs on productivity. There is a manager who said that in 29 years of working in this industry he has never seen something that has impacted workers as much as this HERhealth curriculum." Several Share Hope Peer Educators also shared their stories, including Nadege, who participated in the program, and attributes all of her knowledge about family planning to the education she received at work, saying "Before, I just used to hear about [family planning] by word of mouth. . . . But now it's completely different. Share Hope has given us information and an opportunity to learn, to understand, and to practice family planning."
Due to their better

understanding of basic

health practice, 87 percent

of workers reported taking

fewer days off from work because of illness.

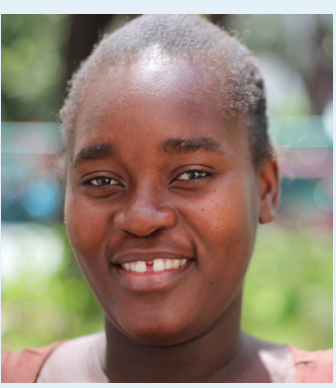

Nadege, who had an unplanned pregnancy at age 17 , and now works to support her three children, stressed the importance of

access to contraception for women in Haiti who want to choose how many children they have in order to afford food, shelter, and school; and ultimately rise out of poverty and advance their careers.

a Interview with Cynthia Petterson, Universal Access Project, United Nations Foundation, http://www. universalaccessproject.org/stories/cynthia/

\section{ACTION 8:}

\section{Leverage resources, know-bow, and networks to expand access.}

While companies with supply chains employing many women are leading the way on investment in women's health, a number of other sectors are stepping up to improve women's health and empowerment by leveraging their resources, expertise, and networks. Companies with communications expertise in particular have begun investing in women's health through the development of mobile apps, creation of compelling media, and use of communications networks. 


\section{CORPORATE highlightS: MTV Staying Alive Foundation with Viacom International, Vodafone Foundation, and Reckitt Benckiser}

Outlined here are three companies using their resources, expertise, and networks to reach girls and women. ${ }^{\text {a }}$

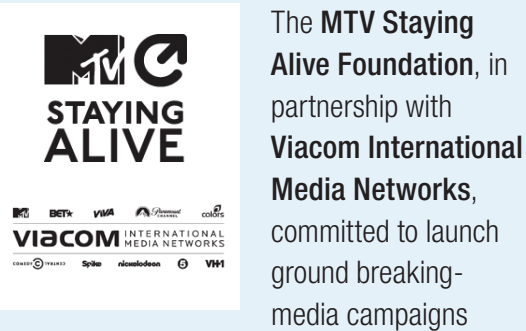

addressing youth sexual health, tied to the popular television show-Shuga - in Nigeria, Egypt, and India, reaching 224 million young people. MTV and Viacom's private sector expertise in the creation and distribution of compelling content on their expansive media networks enables youth-focused contraception messages to reach an unparalleled audience.
Benetton Group, the global fashion brand,

\section{BENETTON} GROUP launched the Women Empowerment Program, of which women's health, including sexual and

reproductive health, is a key pillar. Benetton has partnered with UNFPA to increase visibility of sexual and reproductive health issues through creative communication work, including the "Power her Choices" campaign which aims to raise global awareness on the importance of family planning. Benetton's non-conventional, cutting-edge social communication promises to reach non-traditional audiences and attract more support from the general public.
Reckitt Benckiser and its Durex brand are committing to share the findings and data from their 4th Global Sex Surveythe largest and most

comprehensive global attitudinal survey on social and cultural sex behaviors run in 42 countries across adults 18 years and older. The results of this survey, which includes information on: attitudes towards sex, sexuality and relationships, sexual satisfaction and activity, sex education, contraceptive use, and STIs, is being shared in the effort to assist governments and health institutions, who share their values, and feel as passionate as they do to reduce unintended pregnancies, STIs and sexual violence, with the fundamental objective to better understand attitudes and behaviors when it comes to sex for all genders and sexual orientations.

a Other private sector leaders who recently made commitments to women's health and empowerment at the Family Planning 2020 Summit in London include the Vodafone Foundation, the Chaudhary Foundation, and Tata Trusts. These company commitments can be found at www.summit2017.familyplanning2020.org/newcommitments

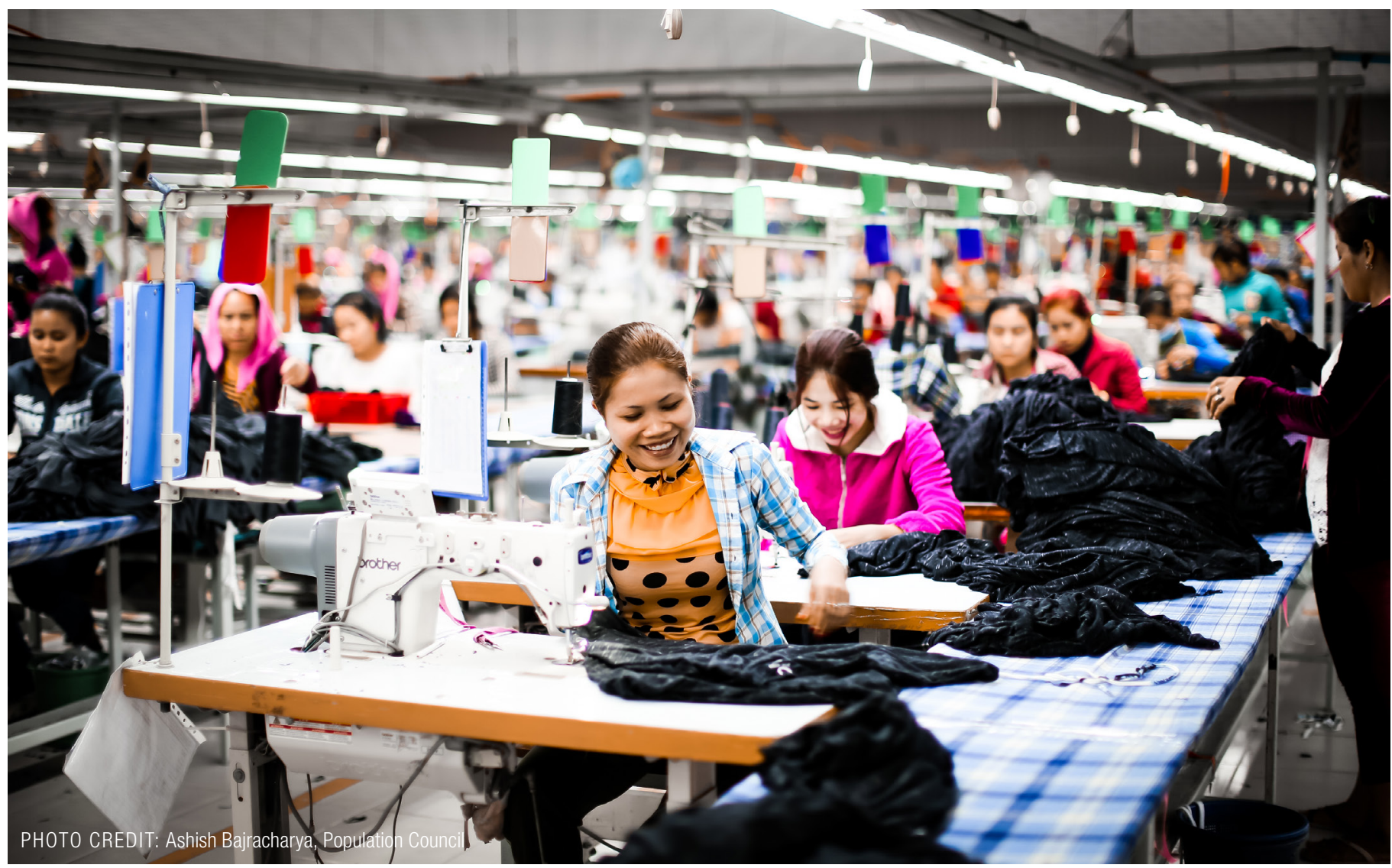


SPOTLGITS FROM AROUND TIE WORLD

More than twenty companies and over a dozen organizations are partnering around the world to implement programs improving women's health and empowerment. From Asia, Africa, and Latin America, below is a snapshot of eleven private sector programs aimed at improving the health and well-being of women and their families. A full mapping of all participants and programs is in ANNEX 2.

\section{Caribbean Apparel-Haiti}

Caribbean Island Apparel SA, an apparel manufacturing company in Port-au-Prince, transformed their onsite clinic with more than 2,600 workers, and provides family planning, gynecological and other services to its workers onsite. The company implemented structural changes to its factory health clinic, including expanding the role of nurses, improving management of clinical services, and establishing clinical quality standards with support from several NGOs. It has been able to sustain these changes without outside funding.

\section{Spark Minda \& Pathfinder International} India-India

Spark Minda, a major Indian automobile component manufacturer, made a commitment to Family Planning 2020 to partner with Pathfinder International India and invest in sensitization workshops on family planning, reproductive health, and menstrual hygiene information and services for its workers. The effort is training 3,000 men and women by 2020 and allocating funds for family planning and feminine hygiene products. The workshops train participants on family planning methods and their effectiveness and address myths and misconceptions. Participants also learn about nearby public family planning services.

\section{Gap Inc. \& CARE-Myanmar}

CARE has been a principal partner in implementing Gap's P.A.C.E. program, which includes women's sexual and reproductive health, in nine countries. The International Center for Research on Women (ICRW) has been the independent evaluator of the P.A.C.E. program since its inception. In its global evaluation, ICRW found that women who participated in P.A.C.E. in Cambodia for example were three times more likely to advance than non-participants in the year following the program.

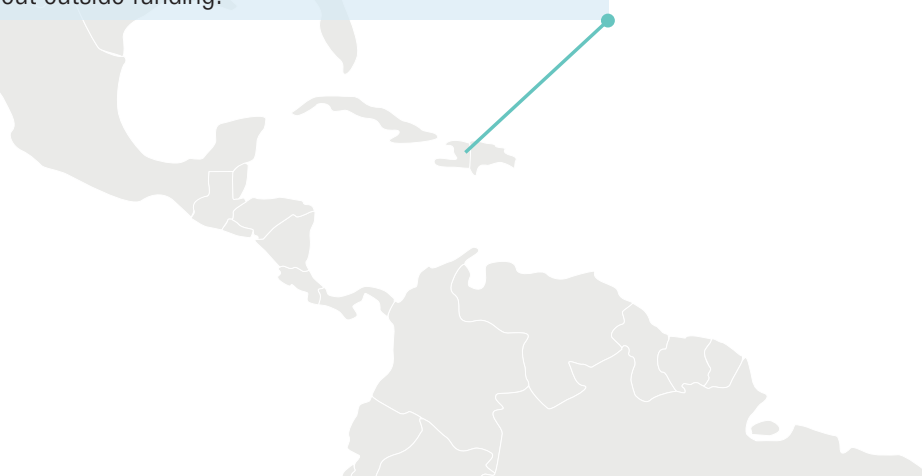

Marie Stopes-Burkina Faso

Marie Stopes Burkina Faso works with the UN Population Fund (UNFPA) to train predominantly male members of the cotton growers' associations, who produce cotton for Sofitex, on family planning. The members conduct sensitization sessions on family planning with their peers, take home information to their partners, and make referrals to family planning services. In 2017, the program reached 11,000 workers and their families, providing 4,100 methods of voluntary family planning.

\section{International Planned Parenthood Federation-Ethiopia}

IPPF's Family Guidance Association of Ethiopia (FGAE) works with over 150 businesses in Ethiopia ranging from textile and garment factories, like the Kombolcha Textile Factory, to flower and horticultural farms including coffee plantations, to engineering and automotive industries and cement factories, reaching 30,000 workers with reproductive health information and services. 


\section{Swasti-India}

Swasti is a health resource center based in India that works with more than 120 factories and has touched the lives of over 186,800 workers. Swasti partnered with the Gap Foundation to develop, pilot, and scale the P.A.C.E. program in seven countries. Swasti also has partnered with Walmart, BSR, LS \& Co., Debenhams, Primark, Motorola, and Inditex on worker initiatives to improve health (including sexual and reproductive health and WASH); reduce gender-based violence; and improve life skills and gender equality. An independent evaluation by Tufts University of the Women in Factories program, implemented by Swasti in India in partnership with Walmart Foundation and CARE, found positive impacts on health, gender equality, and worker-manager relationships.

\section{MAS Holdings-Sri Lanka}

MAS Holdings, based in Sri Lanka, is a \$1.7 billion apparel manufacturer operating 53 manufacturing facilities in 16 countries and supplying products for brands like Victoria's Secret, Nike, Marks \& Spencer, among others. It implements a "Women Go Beyond" program on career advancement, skills development, work-life balance, and health and well-being information and services for its 90,000 employees, 70 percent of whom are women. The program provides in-depth trainings, health and well-being information and services covering reproductive health education, family planning, breast cancer, mental health, STDs and HIV, maternal and infant health, noncommunicable diseases, gender-based violence, and free medical check-ups, in partnership with IPPF's Family Planning Association of Sri Lanka (FPASL).

\section{Takeda-Bangladesh}

Takeda, the largest pharmaceutical company in Japan and Asia, has partnered with BSR's HERproject to perform assessments of 15 factory clinics in Bangladesh. It helped factories upgrade and improve the capacity of their clinics to serve women workers. The clinic upgrades have helped address such challenges as anemia, poor hygiene, inadequate pre- and post-natal care, and other issues facing women workers and improved access to health services and products. Through continued partnership in China, Ethiopia, India, and Kenya, Takeda is implementing HERhealth programs and aims to reach 75,000 workers in 120 factories and farms and 35,000 family and community members.

\section{Auchan Retail, through Weave Our Future Foundation-Vietnam}

Auchan Retail, the French multinational retail group operating in 17 countries with 345,396 employees is investing through its foundation, Weave Our Future, €5.5 million over 5 years in women's health and empowerment programs in Bangladesh, Cambodia, and Vietnam, reaching more than 200,000 people, directly and indirectly. These programs are training factory nurses, medical staff, and peer educators to improve health skills and services provided in factories, with a special focus on the needs of women. Weave Our Future Foundation plans to expand its programs to Myanmar and then to suppliers in Africa.

\section{Li \& Fung-Cambodia}

Li \& Fung, global supply chain manager for leading global brands, has a network of over 15,000 suppliers in more than 40 economies worldwide and has partnered with BSR to implement the HERproject in 87 factories across Bangladesh, Cambodia, India, and Vietnam reaching 178,000 workers. Li \& Fung's investment in HERproject is one of the many ways it works across the industry to reduce risk, improve conditions, and support women's empowerment.

\section{Columbia Sportwear Co._-Indonesia}

Columbia Sportswear Co. has 200 direct suppliers, 15 of which have implemented the HERproject in Vietnam, China, India, Indonesia, and Bangladesh. Peter Haney, Director of Social Responsibility, expressed his support for investing in women's empowerment, saying, "Columbia Sportswear Co. is committed to improving the lives of workers who make our product. We are particularly focused on the female workers as they make up $75 \%$ of the workforce. The HERproject has been very successful in educating and empowering women on critical issues around health and finance." 


\section{BROADER CONSIDERATION}

The eight actions outlined above are a guide to help businesses take swift action for impact. Outlined here are four broader recommendations companies, suppliers, NGOs, civil society, governments and other players should take into consideration as the private sector increases its action on women's health and empowerment.

\section{Take collective action.}

Many women's health and gender equality programs have been implemented, often very successfully but with limited scale or impact. Now is the time for stakeholders to come together to find ways to have collective impact and greater reach. To do so, it is necessary to:

Create a collective action initiative or forum

Develop joint strategies and approaches

Build a repository of program tools and resources

Engage with a wide range of partners and stakeholders

\section{Advocate for government policies that support women's bealth and gender equality}

Government has an important role in addressing the health needs of workers and creating the enabling environment for business to play its part. Advocates need to build linkages between occupational health and public health systems in ways that strengthen each and benefit both the private and public sectors. Key priorities include:

Ensure health facilities are accessible to workers near their workplace or residences and during hours that respond to work schedules.

Ensure workplace health staff and clinics meet basic quality standards.

Create policy alignment on nurse training, referral mechanisms, and products and services between health and safety overseen by ministries of labor and public health overseen by ministries of health.

\section{Reposition women's bealth as integral to equality and a key business investment}

Women's health is an essential component of gender equality. Corporate women's empowerment initiatives need to incorporate women's health broadly and recognize that, for example, the ability to plan their families is a pre-requisite for women, particularly poor women, to become and remain employed and advance professionally. Stakeholders need to:

Ensure women's health and well-being is on the agenda at global business convenings such as the World Economic Forum.

Encourage C-Suite and senior business leaders to speak publicly and privately to their peers at key private sector events on the importance of private investment in women's health and empowerment.

\section{Integrate gender and women's health into standards and certifications.}

Today most standards and certifications for companies focus on safety and injury prevention rather worker well-being. Incorporating women's health and gender equality into these traditional standards and certifications enables businesses to move from risk mitigation to value generation. This will require stakeholder cooperation to:

- Promote gender equity and women's health as priorities in business standards and certifications.

- Use tools, such as the Gender Equality in Codes of Conduct guidance, to integrate women's health into standards and assessments.

Ensure public reporting on women's health as part of the Global Reporting Initiative, UN Global Compact, and other transparency initiatives.

Develop rights-based guidelines for worker health programs rooted in voluntarism and worker demand.

Doing right and doing good are not mutually exclusive but mutually reinforcing. As evidenced by the dozens of companies already investing in women's health and well-being, when women and their families are healthy and empowered they are happier and more productivea win-win for women and for businesses. 


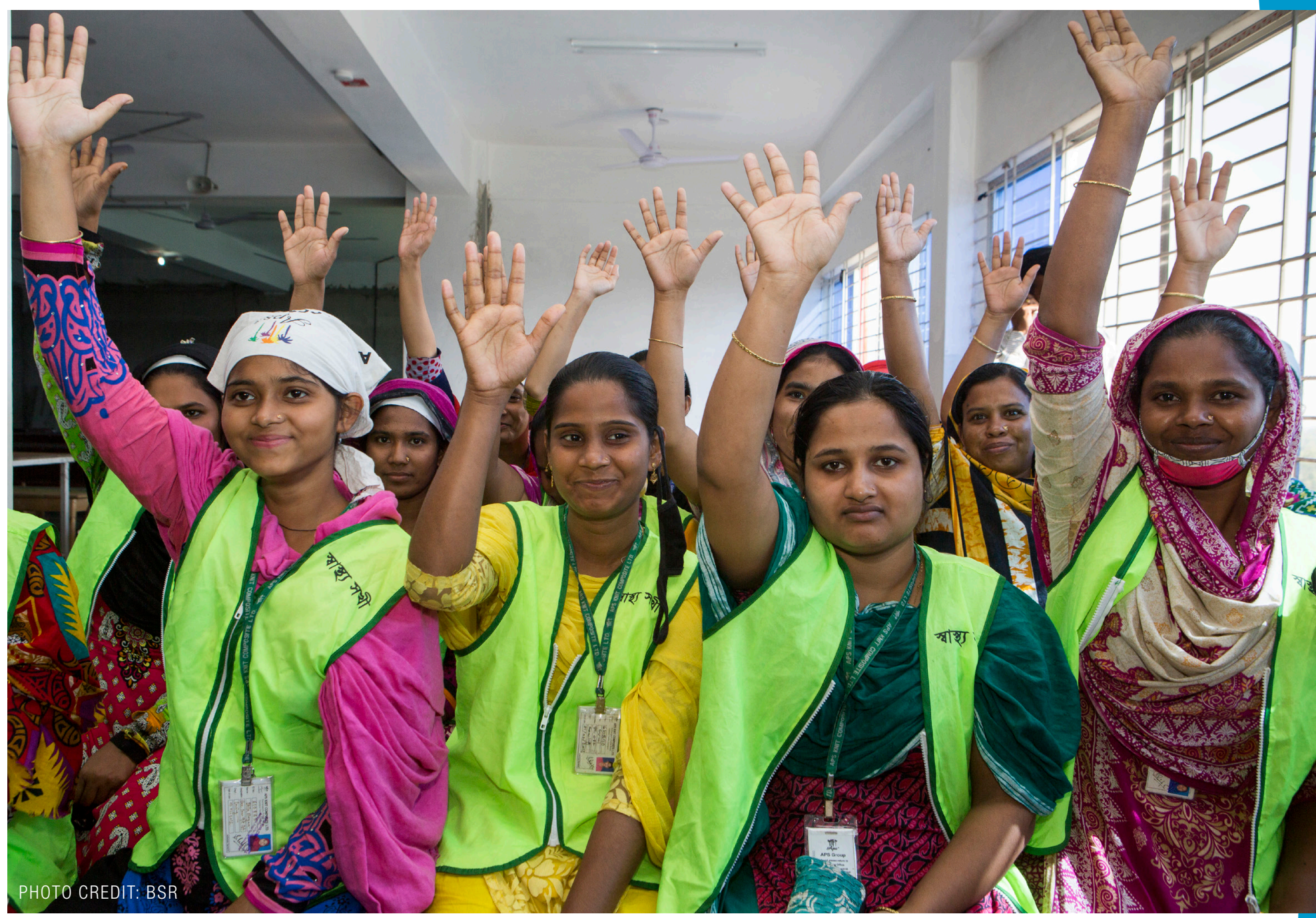

\section{CONCLUSION}

As the global community embarks together on a journey to reach the SDGs by 2030, the private sector is poised to play a significant role: helping save millions of lives, empowering generations to come, and making extreme poverty a thing of the past. Ensuring women and girls are healthy and empowered under SDGs 3 on Health and 5 on Gender Equality are critical in their own right and essential to achieving every other SDG, and the private sector is integral to achieving these goals - realizing both health and business returns.

Doing right and doing good are not mutually exclusive but mutually reinforcing. As evidenced by the dozens of companies already investing in women's health and well-being, when women and their families are healthy and empowered they are happier and more productive - a winwin for women and for businesses. Specifically, companies ensuring access to women's health care such as menstrual hygiene, STI services, maternal health, and reproductive health, so women can plan their families; investing in skills building in literacy and communication; and promoting initiatives encouraging equality and ending discrimination are seeing significant returns on investment through improved efficiency, reduced turnover, and market differentiation. Companies investing in ethically made products can also differentiate themselves in the market and engender customer loyalty.

Apparel, agriculture, electronics, shoes, and consumer goods companies with vast supply chains employing many women are particularly well positioned to ramp up health and well-being programs. And communications companies and others interested in gender equality are also beginning to use their expertise and networks to reach more women and girls with health and empowerment information. To date, most investments have been time-bound and project-based, but these programs have built a clear case for expanded initiatives, and now is the time to move investments in women's health and empowerment out of the margins and into mainstream business practices. The case is clear, the time is right, and the global development community stands ready to partner. It's time to act. 
ANNEX 1:

\section{ORGANIZATIONS FEATURED}

Through its collaborative initiative HERproject, BSR has worked with over 60 companies in 14 countries and more than 600 factories and farms to implement women's health and empowerment programs. Active in supply chains including apparel, agriculture, and electronics, HERproject has reached over 700,000 women. HERproject consists of three pillars - HERhealth, HERfinance, and HERrespect- that use peer-to-peer training and access partnerships to empower women. Contact Andrea Lilja, alilja@bsr.org, getinvolved@herproject.org or visit www.herproject.org.

CARE works in 94 countries and partners with numerous companies across Bangladesh, Cambodia, Indonesia, Myanmar, and Vietnam to design and implement a variety of workplace health and empowerment programs to ensure workers have the information and services they need. Contact Mariela Rodriguez, mrodriguez@care.org or visit www.care.org.

ICRW Advisors, supports business leaders to achieve social and organizational change on gender equality and women's empowerment. Services span conducting gender diagnostics, providing strategic guidance, designing initiatives and policies, measuring impact, and conducting training and workshops. Contact Genevieve Smith, gsmith@icrw.org, or visit www.icrwadvisors.org.

International Planned Parenthood (IPPF) works through its national affiliates in over 170 countries to partner with dozens of companies in more than six countries to provide a wealth of experience delivering health services in the workplace, improving the capacity of workplace clinics, strengthening referrals to service providers, and leading advocacy to improve worker health. Contact Emma Bakhle, ebakhle@ippf.org or visit www.ippf.org.

Marie Stopes International (MSI) operates in 37 countries working with over 50 companies in Bangladesh, Cambodia, Vietnam, Burkina Faso, and Ethiopia to increase awareness of and access to sexual and reproductive health, foster support for such programs with factory management, improve factory clinics, and bolster referrals for needed services. Contact Meghan Blake, meghan.blake@mariestopes.org or visit www.mariestopes.org.

Meridian Group International, Inc. is a woman-owned, small business that has partnered in more than 20 countries with corporations, international agencies and NGOs to implement good workplace practices on women's health and gender equality. It also advocates for global and national policy change on corporate standards on these issues. Contact d.wofford@meridian-group.com or visit www.meridian-group.com.
Pathfinder International operates in 19 countries around the world to expand access to contraception, promote healthy pregnancies, save women's lives, and prevent the spread of HIV. Pathfinder has partnered with a number of companies in India, Bangladesh, and China to provide workplace women's health programs. Contact Suzanne Rexing, srexing@pathfinder.org or visit www.pathfinder.org.

Population Council has conducted research on women's health needs and programming and evaluated workplace interventions in factories in Cambodia and Bangladesh. The Council partnered with health NGOs like CARE, Marie Stopes and Save the Children to help the Ministry of Labor and Vocational Training develop new guidelines for workplace infirmaries that highlight good clinical practices, including for women's health. In Bangladesh, the Council conducted a rigorous evaluation of the HERproject intervention. Contact Ashish Bajracharya, abajracharya@popcouncil.org or visit www.popcouncil.org.

Swasti, a health resource center based in India has worked with more than 120 factories and corporations in India and Sri Lanka on improving workplace health and rights, reaching over 186,000 workers. Contact Joseph Julian K G, julian@swasti.org or visit www.swasti.org.

UNFPA works in over 150 countries as the largest multilateral reproductive health provider, providing sexual and reproductive health experts, strengthening supply chains, and working with companies to design workplace programs to promote the wellbeing of female employees. Contact Elena Pirondini, pirondini@unfpa.org.

United Nations Foundation (UNF) works with dozens of multinational corporations, connecting them with the United Nations, supporting their efforts to achieve the Sustainable Development Goals, convening key stakeholders at strategic moments, partnering on thought leadership, and developing communications strategies to lift up the global development work of private sector leaders. Contact Robyn Russell, rrussell@unfoundation.org or Ilze Melngailis, imelngailis@unfoundation.org. 


\section{South Asia and China}

\section{Bangladesh}

- Levi Strauss \& Co. implementing their Worker Well-being initiative

- Auchan Retail through its foundation-led Weave Our Future program implementing women's health and empowerment programs

- Lindex \& BSR implemented HERhealth, now with BSR \& GIZ launching WE WOMEN, a program to provide technical, financial, and health training to garment workers

- ANN INC. \& BSR implementing HERhealth

- Gap Inc. \& CARE implementing P.A.C.E.

- Li\&Fung \& BSR implementing HERhealth and HERfinance

- Takeda supporting BSR's implementation of HERhealth and factory improvement.

- Walmart Foundation \& CARE partnered to implement the Women in Factories Initiative to empower garment workers with life skills on communications, hygiene, reproductive health, occupational health and safety, gender sensitivity, and leadership training to support career development, reaching 50,000 workers in 150 factories

- GlaxoSmithKline, Marks \& Spencer \& CARE are partnering to implement Health Access and Linkage Opportunities for Workers (HALOW) to reach garment workers with health, hygiene, and nutrition information; improve factory clinics; and connect workers with health services.

- Galaries Lafayette \& CARE are partnering to implement the Promoting and Enabling Environment for Women in Factories program which provides health and empowerment training to workers and supervisors, trains peer facilitators, builds capacity of worker committees to support dialogue, and coordinates with health providers to ensure delivery of services to workers.

- MSI, with support from Embassy of the Kingdom of the Netherlands, works with the readymade garment factories and other industries including rice mills, brick kiln factories, jute mills, cement factories, and shrimp cultivation and export processing companies to train company management on the importance of sexual and reproductive health and women's empowerment, increase provisions of reproductive health information to workers, and improve referrals for health services, reaching 20,000 factory workers.

- CARE, the European Union \& Austrian Development Agency are partnering to implement the OIKKO program to increase the influence of female garment workers, organized labor, and civil society. Trainings include reproductive and sexual health and empower workers to negotiate for access to needed services.

- Pathfinder's Health Service Delivery Project, funded by USAID and DfID, trains health workers at garment factory clinics on reproductive health and provides information to factory owners, managers and staff, serving 9,327 women workers in 13 clinics.

- Swasti supported scale up of P.A.C.E.

- The Population Council partnered with BSR to evaluate HERhealth in 10 factories, including four comparison factories, finding positive impacts on reproductive health knowledge and behaviors.
- Meridian International, Inc. with ILO/IFC Better Work program, BSR, and brands is making health education materials on family planning, hygiene and engaged fatherhood easily available in factories.

\section{China}

- Jabil \& BSR implementing HERhealth

- Levi Strauss \& Co. implementing the Worker Well-being initiative

- Columbia Sportswear Co. \& BSR implementing HERhealth

- Lindex plans to partner with BSR and GIZ to implement WE WOMEN

- ANN INC. \& BSR implementing HERhealth

- Gap Inc. implementing P.A.C.E.

- Takeda implementing HERhealth with BSR

- Qualcomm partnering with BSR to create a mobile app to provide workers with health information and connect them with services.

- Swasti supported scale up of P.A.C.E.

- Pathfinder International and UC Berkeley promote sexual and reproductive health for migrant workers' in 30 factories, serving 25,000 workers.

India

- Levi Strauss \& Co. implementing the Worker Well-being initiative

- Jabil plans to partner with BSR to implement HERhealth

- Columbia Sportswear Co. \& BSR implementing HERhealth

- Lindex \& BSR implementing HERhealth, plans to partner with BSR \& GIZ to implement WE WOMEN

- ANN INC. \& BSR implementing HERhealth

- Gap Inc. implementing P.A.C.E.

- Li\&Fung \& BSR implementing HERhealth and HERfinance

- Takeda implementing HERhealth with BSR

- Marks \& Spencer \& BSR implementing HERrespect to provide gender equality training and improve health

- MTV Staying Alive Foundation \& Viacom International Media Networks launching television show addressing youth sexual health

- The Tata Trusts, supported with profits from the Tata companies investing $\$ 10$ million to provide access to reproductive, maternal, newborn, child, and adolescent health services

- Spark Minda \& Pathfinder International partnering to provide reproductive health, including family planning and menstrual hygiene, workshops to workers in supply chain

- IPPF's Family Planning Association of India (FPA India) works with construction workers and power loom operators to provide counseling and testing for sexually transmitted infections and HIV as well as support for wider occupational health issues. FPA India also works with the Association of Power-Loom Owners to ensure workers have access to health services. 


\section{South Asia and China (continued)}

- Swasti partnered with over 120 factories to implement worker wellbeing initiatives to improve health; including sexual and reproductive health and rights and WASH; reduce gender-based violence; and improve life skills and gender equality.

\section{Nepal}

- Chaudhary Foundation, philanthropic arm of CG Corp Global, partner with Government Nepal to strengthen family planning uptake

\section{Sri Lanka}

- Levi Strauss \& Co. implementing their Worker Well-being initiative

- Gap Inc. \& CARE implementing P.A.C.E.

- MAS Holdings implementing its Women Go Beyond program providing trainings on career advancement, skills development, and health information and services

- IPPF's Family Planning Association of Sri Lanka (FPASL) works with more than 20 companies, including MAS Holdings and other garment manufacturers and tea plantations to reach 49,000 workers with reproductive health information and services.

- Swasti worked with LS\&Co. to implement Worker Wellbeing Initiatives in seven factories.

\section{Southeast Asia}

\section{Cambodia}

- Marks \& Spencer partnered with Project Hope \& the Reproductive Health Association of Cambodia (RHAC) on HEALTHWORKS, a program providing health information and services.

- Auchan Retail through its foundation-led Weave Our Future program implementing women's health and empowerment programs

- Lindex plans to partner with BSR and GIZ to implement WE WOMEN

- Gap Inc. \& CARE implementing P.A.C.E.

- Li\&Fung \& BSR implementing HERhealth and HERfinance

- Levi Strauss \& Co. implementing their Worker Well-being initiative

- GlaxoSmithKline, Levi Strauss \& Co., CARE, and Australian Government partnered to implement Chat!, which provides reproductive health information through sessions and a mobile application, reaching 16,000 workers in 31 factories.

- CARE \& Levi Strauss \& Co. have partnered on the Sewing for a Brighter Future program to address the sexual, reproductive and maternal health, HIV/AIDS, nutrition, financial literacy, sexual harassment, and HIV/AIDS needs of garment workers, reaching 10,000 female workers.

- Marie Stopes Cambodia (MSC) has worked with DFAT Australia and USAID to implement two programs to improve sexual and reproductive health information and services to approximately 70,000 garment workers in 41 factories in Cambodia who supply for brands such as H\&M, TESCO, and MGT.

- IPPF's Reproductive Health Association of Cambodia (RHAC) works with more than 50 factories, primarily in the garment sector, covering more than 100,000 factory workers to provide reproductive health information, including on family planning, sexually transmitted infections, and HIV/AIDS; improve the capability of factory clinics and service providers, and strengthen the referral system to ensure access to quality health services.

- Swasti supported scale up of P.A.C.E.

- The Population Council, with support from USAID and H\&M, generating evidence on reproductive health needs and living conditions of female garment workers.

\section{Indonesia}

- ANN INC. \& BSR implementing HERhealth

- Columbia Sportswear Co. \& BSR implementing HERhealth

- Gap Inc. \& CARE implementing P.A.C.E.

- The Indonesia Planned Parenthood Association (IPPA) collaborates with a range of major employers from garment and shoe factories, hospitality and construction, to plantations and a local airline to 45,000 workers with reproductive health information and services.

- Swasti supported scale up of P.A.C.E. 


\section{Southeast Asia (continued)}

\section{Myanmar}

- Lindex plans to partner with BSR and GIZ to implement WE WOMEN

- Gap Inc. \& CARE implementing P.A.C.E.

\section{Philippines}

- NST/Hamlin partnering with UNFPA to provide garment workers with information and services on family planning, maternal health, and basic health care.

- CARD-MRI partnering with UNFPA to provide women in micro-finance network with reproductive health information and services.

- ANN INC. \& BSR implementing HERhealth

\section{Vietnam}

- Levi Strauss \& Co. implementing their Worker Well-being initiative

- Jabil partnering with BSR to implement the HERhealth program

- Columbia Sportswear Co. \& BSR implementing HERhealth

- ANN INC. \& BSR implementing HERhealth

- Auchan Retail through its foundation-led Weave Our Future program implementing women's health and empowerment programs

- Gap Inc. \& CARE implementing P.A.C.E.

- Li\&Fung \& BSR implementing HERhealth and HERfinance

- Marks \& Spencer \& BSR implementing HERhealth

- IPPF's Vietnam Family Planning Association (VINAFPA) works with more than 20 companies to provide sexual and reproductive health information and services to 21,000 workers in the clothing, footwear and canned food industry.

- Marie Stopes Vietnam has partnered with the Pou Chen Group - the largest branded athletic and casual footwear manufacturer in the world producing for major brands such as Nike, Adidas, Asics, Clarks, Reebok, Puma, New Balance, Crocs, Merrell, Timberland, Converse and Salomon - providing sexual and reproductive health information to 491,000 female workers services to over 50,000 female workers

- Swasti supported scale up of P.A.C.E.

\section{Central America}

\section{El Salvador}

- Gap Inc. implementing P.A.C.E.

\section{Guatemala}

- Gap Inc. implementing P.A.C.E.

\section{Haiti}

- Share Hope \& BSR implementing HERhealth

- Levi Strauss \& Co. implementing their Worker Well-being initiative

- Gap Inc. \& CARE implementing P.A.C.E.

\section{Mexico}

- Gap Inc. implementing P.A.C.E.

\section{Nicaragua}

- Gap Inc. implementing P.A.C.E. 


\section{Africa}

\section{Burkina Faso}

- Marie Stopes Burkina Faso works with UNFPA to train members of the cotton growers' associations, who produce cotton for Sofitex and are men, to conduct sensitization sessions on family planning with their peers, to take home information to their wives, and to make referrals to family planning services, reaching 11,000 workers and their families.

\section{Egypt}

- Levi Strauss \& Co. implementing their Worker Well-being initiative

- MTV Staying Alive Foundation \& Viacom International Media Networks launching television show addressing youth sexual health.

\section{Ethiopia}

- Kombolcha Textile Factory in Ethiopia, which produces bed sheets and employs more than 2,200 workers, half of whom are women, partnered with IPPF's Ethiopia, Family Guidance Association of Ethiopia, to set up clinics for workers delivering a range of sexual and reproductive health services.

- Takeda implementing HERhealth with BSR

- Gap Inc. \& CARE implementing P.A.C.E.

- IPPF's Family Guidance Association of Ethiopia (FGAE) works with over 150 businesses in Ethiopia ranging from textile and garment factories, and flower and horticultural farms including coffee plantations to engineering and automotive industries and cement factories, reaching 30,000 workers with reproductive health information and services.

- Marie Stopes, supported by the Embassy of the Kingdom of the Netherlands, has worked with 18 manufacturing companies including flower and herb farms, leather and textile factories, pharmaceutical factories, and sugar factories to train heath workers to provide on-site reproductive health counseling and services to employees, reaching 23,037 female workers.

\section{Kenya}

- Twinings \& BSR implementing HERhealth to reach tea workers and smallholder farmers

- Takeda implementing HERhealth with BSR

- Marks \& Spencer partnered with VP Group \& BSR to implement HERhealth at 11 farms and packhouse sites.

- The Danish Family Planning Association, an NGO, with local partners, is implementing workplace programs with companies in Kenya and Uganda in the garment, pharma, flower and security sectors, reaching 6,630 employees with sexual and reproductive health information or services. 


\section{ACKNWLEDGEMENTS}

\section{Co-Authors}

Robyn Russell and IIze Melngailis at the UN Foundation

Andrea Lilja, Elissa Goldenberg, and Lisa Staxang at the BSR

Carolyn Rodehau and David Wofford at the The Evidence Project/

Meridian Group International, Inc.

\section{Special thanks}

Vincent Jurlano, Lewelyn Baguyo, and Elena Pirondini at the United Nations Population Fund

Kim Almeida at the Levi Strauss Foundation

Jeannette Ferran Astorga and Nicole Parisi at ANN INC.

Kindley Walsh-Lawlor and Sasha Radovich at P.A.C.E. at GAP Inc.

Laura Hawkesford at Marks \& Spencer

Elisabeth Hedberg and Ingrid Porss at Lindex

Cynthia Petterson at Share Hope

Lisa Allison and Graeme Elder at Jabil

Celine Gilart and Francesca Copleston at Twinings

Marilyn Manila at CARD-MRI

Catherine Baybay at NST

Annie 0'Connor at ICRW Advisors

Melanie Minzes, Mariela Rodriguez, Joe Sutcliffe, and Kate Barwise at CARE

Emma Bakhle at the International Planned Parenthood Federation

Meghan Blake at Marie Stopes International

Sono Aibe at Pathfinder International

Kelsey Carroll, Kate D'Amico, Justine Desmarais and Seema Jalan at the Universal Access Project at the UN Foundation

Mary-Ann Etiebet and Naveen Rao at Merck for Mothers ${ }^{20}$

20 The activities discussed in this publication were supported by funding from Merck through an award agreement with its Merck for Mothers Program. The content of this publication is solely the responsibility of the author(s) and does not represent the official views of Merck. 
